\title{
Epididymo-Orchitis in Pre-Pubertal Children. Epidemiology, Etiology, Management and Follow-Up Recommendations"
}

\author{
Sarel Halachmi ${ }^{1 \#}$, Neri Katz ${ }^{2}$ \\ ${ }^{1}$ Pediatric Urology Service, Bnai Zion Medical Center, Faculty of Medicine, Technion, \\ Israeli Institute of Technology, Haifa, Israel \\ ${ }^{2}$ Neonatal Intensive Care Unite, Eadith Wolfson Medical Center, Holon, Israel \\ Email: " sarel.halachmi@b-zion.org.il
}

Received March 26, 2013; revised April 23, 2013; accepted April 30, 2013

Copyright (C) 2013 Sarel Halachmi, Neri Katz. This is an open access article distributed under the Creative Commons Attribution License, which permits unrestricted use, distribution, and reproduction in any medium, provided the original work is properly cited.

\begin{abstract}
Epididymo-Orchitis (EO) is a disease that may affect males in all ages. Neonates and elderly patients may suffer from bacterial infection due to congenital or aging processes affecting the urinary tract. In sexually active post pubertal and young males sexually transmitted organisms may cause EO. EO is also prevalent in pre pubertal healthy boys; however in this group the etiology, the needed imaging modalities and proper management are not clearly defined yet. This manuscript will systematically review the various etiologies causing EO in pre-pubertal boys, discus about the needed proper imaging, and image interpretation, will give treatment and follow-up recommendations.
\end{abstract}

Keywords: Gonad; Inflammation; Infection; Pre-Pubertal; Boys; Etiology; Management; Treatment

\section{Prevalence of Epididymo-Orchitis in Prepubertal Children}

Epididymo-Orchitis (EO) in prepubertal children was thought to be a rare phenomenon. Anderson et al. [1] in 1985 diagnosed EO in 17 out of 113 boys (15\%) presented with acute scrotum. However, the data presented in several other newer studies should change this attitude. Lewis et al. [2] analyzed retrospectively the distribution of the various etiologies for acute scrotal pain in children admitted to the emergency room over a period of 2 years. In this group, $81 \%(192 / 238)$ of the boys were diagnosed having an "inflammatory" process: 46\% (109/238) due to torsion of the appendix testis/epididymis and 35\% (83/ 238) due to inflammation of the gonad. For comparison only, 16\% had torsion of the testis in this study. Klin et al. [3] estimated that the prevalence of EO is $65 \%$ in a retrospective analysis of 65 children who were referred within 5 years due to acute scrotal pain, 42 (65\%) had

\footnotetext{
*Funding source: No funding was secured for this study.

Financial disclosure: the authors have no financial relationships relevant to this article to disclose.

Conflict of interest: The authors have no conflicts of interest to disclose.

${ }^{\#}$ Corresponding author.
}

"epididymitis" and $5(8 \%)$ had torsion of the appendix testis; 12 patients $(18 \%)$ had torsion of the testis. Ben Chaim et al. [4] described the surgical findings in 70 children who underwent exploration of the scrotum due to acute pain. In this series $24 / 70$ (34\%) had testicular torsion and the remaining $46(66 \%)$ suffered from inflammation, $33(47 \%)$ due to torsion of the gonad appendages and the remaining 13 had undefined inflammation. Halachmi et al. [5] reported about 193 consecutive patients diagnosed with EO admitted to the emergency room during period of 5 years. The rate of EO could be estimated as $\sim 60 \%$ as the rate of acute scrotum referals in this period was retrospectively estimated to 322 patients. McAndrew et al. [6] showed that EO and torsion of the gonadal appendages were a frequent event among 100 children admitted with scrotal pain during a time period of 14 months. Seventy boys (70\%) had torsion of the gonad appendix and 12 had inflammation. There were, overall, 8932 general admissions in the same period of time giving an overall incidence of $0.8 \%$ for $\mathrm{EO}$ patients in the pediatric emergency room. Somekh et al. [7] estimated the prevalence of EO in children to be $1.2 / 1000$ children/year.

In summary the data from the above-mentioned re- 
search proved that inflammation of the gonad in prepubertal children is indeed not a rare event among children admitted to the emergency room and it is very prevalent $(60 \%-70 \%)$ in boys presenting with acute scrotal pain.

\section{Etiology for Epididymo-Orchitis in Prepubertal Children}

\subsection{Infectious Causes}

\subsubsection{Congenital Malformations and Coliform Bacterial Infection}

Bacterial infection of the gonad and the urinary tract in pre-pubertal boys may lead to serious illness and to the diagnosis of a congenital malformation [8]. Posterior urethral valve, ectopic ureter $[9,10]$, imperforated annus and neurogenic bladder can all presents with EO. Siegel et al. [8] described a group of 17 pre-pubertal children hospitalized for EO. Eight out the 17 (47\%) had some form of urinary tract malformation and indeed 6 (75\%) of them had coliform bacterial EO. Shirkishi et al. [11] described a case of 14 years old boy with complex malformation including imperforated annus and posterior urethral valve suffering from recurrent bacterial EO resolved after reconstruction and valve ablation. Williams et al. [12] described the relationship between anorectal malformations and the associated urological problems, including bacterial inflammation of the testis and the epididymis. Neurogenic bladder and patients performing clean intermittent catheterization can also present with acute bacterial EO $[13,14]$.

Bacterial infection mandates appropriate antimicrobial therapy and further evaluation of the urinary tract by a pediatric urologist. Following acute treatment and until full evaluation and proper definition of the urinary tract anatomy and physiology prophylactic antibiotics treatment should be considered positively.

In summary, congenital anatomical and neurological malformations of the genitourinary system may lead to bacterial infection of the urinary tract that involves the gonad.

\subsubsection{Non-Coliform Bacterial Infection}

Brucellosis [15] and tuberculosis [16] mainly, may cause non-coliform EO.

Brucellosis EO is a relatively rare phenomena but should be suspected in the presence of other symptoms such as fever, fatigue, arthritis, head ache, lymphadenopathy and heapto-splenomegaly. Positive history for unpasteurized dairy food consumption or direct contact with farm animal may also lead to the diagnosis. High suspicion is needed to diagnose gonadal brucellosis and in case of a doubt consultation with infectious disease specialist is recommended. Definite diagnosis is done by serological or genetic tests.

Tuberculosis (TB) is also a rare condition causing EO $[17,18]$, however in the western world due to immigration and traveling of people from countries with a high incidence of TB disease still exists [19] and physicians should have a high clinical suspicion in these cases. Mycobacterium infects the gonad by hematogenous spread causing chronic inflammation and fibrosis. In more advanced cases caseous foci, scrotal ulceration and testis enlargement mimicking gonadal malignancy may be seen. Diagnosis is by serologic or genetic identification of the mycobacterium or by direct staining and visualization; treatment should be given under the direction of infectious disease specialist.

In summary special non-coliform organisms can cause EO. Careful medical history and high clinical suspicion may lead the physician to accurate diagnosis of brucellosis or TB EO.

\subsubsection{Viral Infection}

Somekh et al. [7] investigated the etiology causing EO in 44 children; only one of them $(2.7 \%)$ had positive urine culture. In $20 \%$ of the patients serological evidence for recent viral infection was discovered. All 43 children were treated conservatively and recovered spontaneously. The authors suggested that epididymitis in boys was not rare and mostly an inflammatory phenomenon (presumably postviral infectious) with a benign course. Greenfield et al. supported the etiology of viral infection as the cause for EO in a review of nine cases of epididymitis due to Haemophilus influenza type b infection. Tassar et al. [20] described a rare case of epididymitis related to acute hepatitis B infection. Orchitis is a well-known common complication of mumps infection usually affecting peri-pubertal boys [21].

In summary viral infection and post viral infection may cause EO. As we do not use routine specific markers to diagnose viral infection in these patients we can assume that the unspecific cases can be related to this etiology and we can also assume that this is the most common cause of EO.

\subsection{Noninfectious Causes of EO}

\section{Torsion of the Gonadal Appendages}

The gonad appendages are remnant of the mullerian duct. During the embryonic life and sexual male differentiation, the developing Sertoli cells secrete in response to the SRY protein a glycoprotein hormone called mllerianinhibiting substance (MIS). MIS causes a rapid regression of the paramesonephric mullerian ducts between the 8th and 10th weeks. Appendix epididymis and paradidymis arise from the mesonephric ducts. These remnants have oval or cylindrical shape 2 - 4 millimeters long at- 
tached to the gonad on a narrow base. The discrepancy between the organ length and narrow base makes it prone to spontaneous torsion, inflammation and necrosis.

In the early stages torsion of the gonad appendages can be easily diagnosed by physical examination and Doppler ultrasound of the scrotum. Physical examination at early stages may localize the pain to the upper pole of the testis or epididymis. Torsion of the appendix testis can be easily detected by ultrasound (US) in early stages of the torsion, as an a-vascular structure, however if the patient arrives to the hospital several days after the initiation of the torsion, probably the whole gonad will be inflamed and the appendages will not be identified sonographically because of the inflammatory background, leading to a non-specific sonographic picture $[22,23]$. Since this phenomenon is prevalent we can assume that a high percentage of nonbacterial incidence of EO may be patients with gonad appendages torsion arriving late to seek medical attention.

Ben Chaim et al. [4] analyzed the surgical findings of 70 children undergoing exploration for acute scrotal pain. Torsion of the gonadal appendix was found in $33(47 \%)$ of the children, as the cause for the inflammation. Hegarty et al. [24] published similar results in a series of 100 consecutive boys with scrotal pain who had scrotal surgical exploration, showing a rate of $32 \%$ of gonadal appendage torsion, and $20 \%$ gonadal nonbacterial inflammation. McAndrew et al. [6] found a 70\% rate of torsion of the appendix testis in 100 consecutive patients admitted because of scrotal pain during a period of 14 months.

Torsion of the testicular appendages is a self-limited condition. Since the cause of the inflammation is "mechanical" there is no need to give antimicrobial therapy. Patients should be treated by non-steroidal anti-inflammatory drugs (NSAIDS) and rest. The inflammatory process recovery varies between few days to 3 - 6 weeks.

In summary, torsion of the testicular appendages is a very common finding in boys with acute scrotum (up to $30 \%-70 \%$ ), it may be even more prevalent, however if the patients arrives during the late stage only nonspecific inflammation will be seen. Torsion of the testicular appendages is a self-limited process, and should be treated with NSAIDS and rest.

\subsection{Imaging Studies}

\subsubsection{Imaging of the Scrotum during the Acute Episode Phase}

Torsion of the testis is above all an emergency medical situation; all patients with acute scrotum should be immediately evaluated by a pediatric urologist or pediatric surgeon to rule out this diagnosis and manage the case properly regarding examination, imaging, and issues re- lated to an immediate operation if needed.

Doppler ultrasound imaging of the gonad is the main tool to evaluate patients with acute scrotum [25-27]. Routine scrotal exploration is no longer recommended for children with an acute scrotum whose Doppler ultrasound demonstrated blood flow to the testis [28]. Clinical judgment of a skillful surgeon is always a crucial factor [29]. The testis, epididymis, and gonadal appendages are well visualized during elective scrotal ultrasonography [30]. The sonographic appearance of torsed gonadal appendix was clearly described in the medical literature $[31,32]$. The twisted appendix is enlarged and hypoecoic in the acute phase. (The) identification of a testicular appendage larger than $5.6 \mathrm{~mm}$ is suggestive of torsion. The situation may be accompanied by hydrocele and thickening of the scrotal wall, enlargement of the head of the epididymis, and increased testicular blood flow. Halachmi et al. [5] repeated scrotal ultrasound in a child with clear sonographic diagnosis of gonadal appendix torsion. Within $24-36 \mathrm{~h}$ following the first ultrasound, the whole epididymis and then the testis became inflamed, showing nonspecific inflammation masking the ability to identify the torsed appendix. Hence, children with torsed gonadal appendix presenting a few days after the beginning of symptoms may not be diagnosed sonographicaly, probably explained by the non-significant sonographic findings of inflammation in many cases.

In summary Doppler ultrasound is the main tool to rule out torsion and diagnose torsion of the appendix testis. In late phase cases a nonspecific inflammation is seen in the gonad.

\subsubsection{Further Imaging of the Urinary Tract System}

Proven bacterial urinary tract infection mandates full evaluation of the urinary tract including invasive studies. Siegel et al. [8] demonstrated variety of urogenial anomalies in patients with bacterial EO. Another important conclusion from this work was the fact that there is no need for any further imaging studies for patients with nonbacterial inflammation. Halachmi et al. [5] retrospectively described 31 patients that had additional imaging after being diagnosed with nonbacterial inflammation. In all 31 patients imaging studies, renal ultrasound, IVP, and voiding cysto-urethrography (VCUG) were normal, and did not show any pathology. Cappele et al. [33] performed ultrasound and VCUG in 38 patients with acute epididymitis; 12 (31\%) bacterial infection, $26(79 \%)$ nonbacterial. Only seven patients $(18 \%)$ had any urinary tract anomaly, of which some were not directly associated with the EO, such as renal malrotation and ureteropelvic junction obstruction. The remaining anomalies included vesicoureteral reflux, obstructing ureterocele, seminal vesicle reflux, and utricular reflux. The patient with the ureterocele was the only one who underwent 
corrective surgery. The authors concluded that with negative history for urological anomaly in addition to nonbacterial EO, further imaging investigation of the urinary tract should be performed only after the second episode.

In summary besides scrotal imaging further imaging of the urinary tract should be performed only in case of positive history for urinary tract anomaly, and in case of bacterial infection. Choosing proper imaging should be done following consultation with pediatric urologist.

\subsection{Management}

Figure 1 summarizes our recommendation for patient's evaluation and management.

Careful history and physical examination are always key points for an accurate diagnosis. Usually torsion of the testis is accompanied by an abrupt severe pain, while torsion of the gonad appendages is usually accompanied by gradual discomfort, and pain that may be more prominent during physical activity and can be partially relieved by rest. Classic appearance of symptoms is not a rule in those situations; hence a good clinical judgment will avoid a missing testis torsion.

Bacterial urinary tract infection should be highly suspected in patients with positive history for urological and

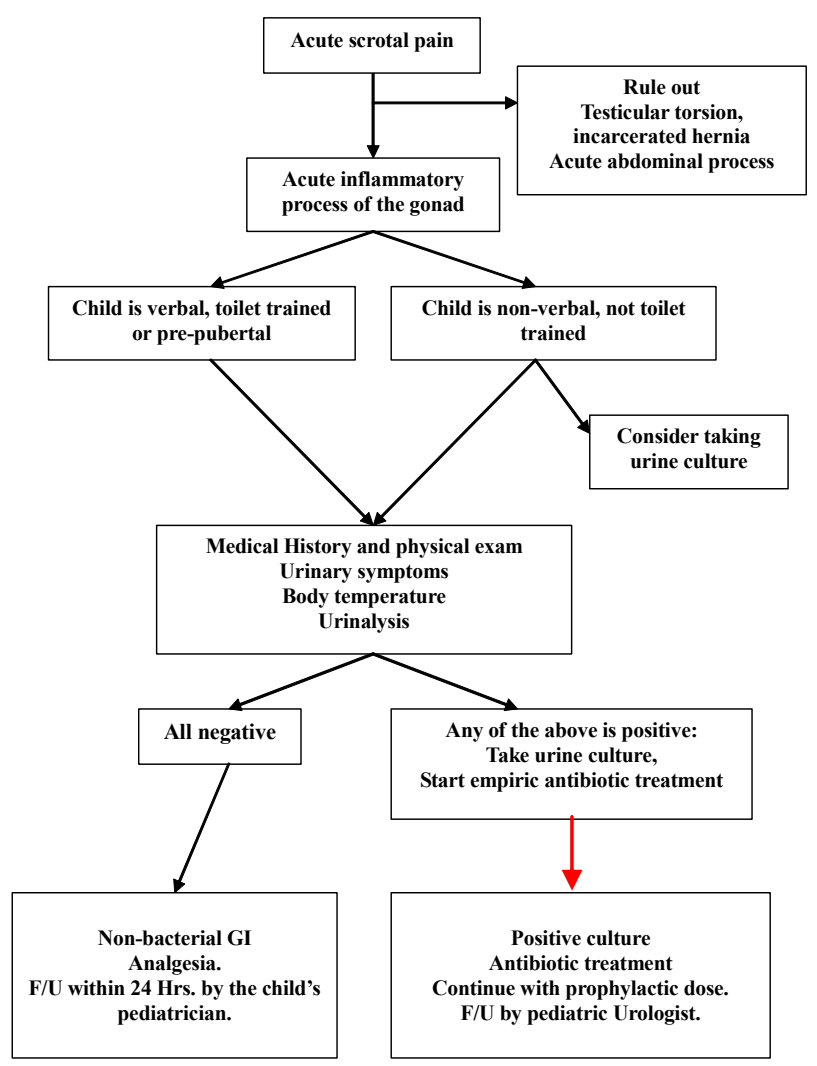

Figure 1. Flow chart, management and follow-up a child with Epididymo-Orchitis. neurourological congenital malformations, and patients presenting with symptoms such as, dysuria, frequency, and urgency. Elevated body temperature, accompanied by general symptoms such as vomiting, apathy, malaise, and abnormal urinalysis, should direct the physician towards bacterial infection. Special care should be taken with young infants and nonverbal children, or persons with intellectual disability. In these groups of patients, accurate medical history may not be properly obtained, and symptoms are not as pathognomonic as in adults [5]. For patients with a high suspicion for bacterial urinary tract infection, a proper management includes: obtaining proper urinary culture, and administration of empiric antibiotics directed towards gram negative bacteria until getting final culture and sensitivity results.

For patients in whom bacterial infection is unlikely, i.e., there is negative medical history, no dysuria, normal body temperature, and clear urinalysis, conservative management including rest, scrotal elevation, and nonsteroidal anti-inflammatory drugs (NSAIDs) is the proper strategy. Somekh et al. [7] showed spontaneous resolution of the inflammation within a week without any treatment beside NSAIDs. Proven torsion of the gonadal appendages is also amenable for the same conservative management, Cappele et al. [33], examined patients with nonbacterial epididymitis treated conservatively 1 month after the acute event, showing complete resolution of the inflammatory process without any effect on the gonad size and consistency. Despite the fact that patients with nonbacterial EO do not present with any typical symptoms of urinary tract infection, there is a nonjustified tendency for the administration of antibiotics. Halachmi et al. [5] showed that unnecessary antibiotic course was given to $142 / 169(78 \%)$ children with nonbacterial EO. Graumman et al. [34] also support these finding, urinalysis of 93 consecutive patients with EO the authors showed that in 92 cases urinalysis was normal and in all 93 cases urine culture was negative.

\subsection{Summary}

EO is prevalent in pre-pubertal boys, according to age stratification, medical history, physical examination and urinalysis the etiology to EO could be identified, and tailored treatment, further imaging or just follow-up could be recommended for each patient. Knowledge of the pathophisiology of EO will avoid unnecessary antibiotic treatment and unneeded imaging of the urinary tract.

\section{REFERENCES}

[1] P. A. Anderson and J. M. Giacomantonio, "The Acutely Painful Scrotum in Children: Review of 113 Consecutive Cases," Canadian Medical Association Journal, Vol. 132, No. 10, 1985, pp. 1153-1155. 
[2] A. G. Lewis, T. P. Bukowski, P. D. Jarvis, J. Wacksman, and C. A. Sheldon, "Evaluation of Acute Scrotum in the Emergency Department," Journal of Pediatric Surgery, Vol. 30, No. 2, 1995, pp. 277-281.

[3] B. Klin, L. Zlotkevich, T. Horne, Y. Efrati, F. Serour and G. Lotan, "Epididymitis in Childhood: A Clinical Retrospective Study Over 5 Years," The Israel Medical Association Journal, Vol. 3, No. 11, 2001, pp. 833-855.

[4] J. Ben Chaim, I. Leibovitch, J. Ramon, D. Winberg and B. Goldwasser, "Etiology of Acute Scrotum at Surgical Exploration in Children, Adolescents and Adults," European Urology, Vol. 21, No. 1, 1992, pp. 45-47.

[5] S. Halachmi, A. Toubi and S. Meretyk, "Inflamation of the Testis and Epidididymis in an Otherwise Healthy Child: Is It a True Bacterial Urinary Tract Infection?" Journal of Pediatric Urology, Vol. 2, No. 4, 2006, pp. 386-389.

[6] H. F. McAndrew, R. Pemberton, C. S. Kikiros and I. Gollow, "The Incidence and Investigation of Acute Scrotal Problems in Children," Pediatric Surgery International, Vol. 18, No. 5-6, 2002, pp. 435-437.

[7] E. Somekh, A Gorenstein and F. Serour, "Acute Epididymitis in Boys: Evidence of a Post-Infectious Etiology," The Journal of Urology, Vol. 171, No. 1, 2004, pp. 391394.

[8] A. Siegel, H. Snyder and J. W. Duckett, "Epididymitis in Infants and Boys: Underlying Urogenital Anomalies and Efficacy of Imaging Modalities," The Journal of Urology, Vol. 138, No. 4, 1987, pp. 1100-1103.

[9] J. F. Squadrito Jr., M. D. Rifkin and S. G. Mulholland, "Ureteral Ectopia Presenting As Epididymitis and Infertility," Urology, Vol. 30, No. 1, 1987, pp. 67-69.

[10] T. Umeyama, T. Kawamura, A. Hasegawa and O. Ogawa, "Ectopic Ureter Presenting with Epididymitis in Childhood: Report of 5 Cases," The Journal of Urology, Vol. 134, No. 1, 1985, pp. 131-133.

[11] K. Shiraishi and H. Takihara, "Recurrent EpididymoOrchitis Caused by Posterior Urethral Valve Associated With Imperforate Anus," International Journal of Urology, Vol. 11, No. 1, 2004, pp. 58-60.

[12] D. I. Williams and J. Grant, "Urological Complications of Imperforate Anus," British Journal of Urology, Vol. 41, No. 6, 1969, pp. 660-665.

[13] B. Karmazyn, M. Kaefer, S. Kauffman and S. G. Jennings, "Ultrasonography and Clinical Findings in Children With Epididymitis, with and Without Associated Lower Urinary Tract Abnormalities," Pediatric Radiology, Vol. 39, No. 10, 2009, pp. 1054-1058.

[14] B. Lindehall, K. Abrahamsson, K. Hjalmas, U. Jodal, I. Olsson and U. Sillen, "Complications of Clean Intermittent Catheterization in Boys and Young Males With Neurogenic Bladder Dysfunction," The Journal of Urology, Vol. 172, No. 4, 2004, pp. 1686-1688.

[15] P. Vogt, P. Francioli, J. Bille and M. P. Glauser, "Brucellosis: A Varied Clinical Presentation in 9 Patients," Schweizerische Medizinische Wochenschrift, Vol. 114, No. 51, 1984, pp. 1906-1909.

[16] A. Chattopadhyay, V. Bhatnagar, S. Agarwala and D. K. Mitra, "Genitourinary Tuberculosis in Pediatric Surgical
Practice," Journal of Pediatric Surgery, Vol. 32, No. 9, 1997, pp. 1283-1286.

[17] D. A. Cabral, H. W. Johnson, G. U. Coleman, M. Nigro and D. P. Speert, "Tuberculous Epididymitis As a Cause of Testicular Pseudomalignancy in Two Young Children," Pediatric Infectious Disease Journal, Vol. 4, No. 1, 1985, pp. 59-62.

[18] L. Mbala, N. Ilunga and K. Kadinekene, "A 3-Year-Old Boy with Tuberculous Epididymo-Orchitis," Tropical Doctor, Vol. 27, No. 1, 1997, pp. 50-51.

[19] Z. Mor, G. Pinsker, N. Cedar, M. Lidji and I. Grotto, "Adult Tuberculosis in Israel and Migration: Trends and Challenges between 1999 and 2010," International Journal of Tuberculosis and Lung Disease, Vol. 16, No. 12, 2012, pp. 1613-1618.

[20] M. A. Tasar, I. Bostanci, B. Karabulut and Y. Dallar, "A Rare Extrahepatic Syndrome Related to Acute Hepatitis Type B: Epididymitis in an Adolescent," Acta GastroEnterologica Belgica, Vol. 68, No. 2, 2005, pp. 270-271.

[21] A. E. Barskey, C. Schulte, J. B. Rosen, E. F. Handschur, E. Rausch-Phung, M. K. Doll, K. P. Cummings, E. O. Alleyne, P. High, J. Lawler, A. Apostolou, D. Blog, C. M. Zimmerman, B. Montana, R. Harpaz, C. J. Hickman, P. A. Rota, J. S. Rota, W. J. Bellini and K. M. Gallagher, "Mumps Outbreak in Orthodox Jewish Communities in the United States," New England Journal of Medicine, Vol. 367, No. 18, 2012, pp. 1704-1713.

[22] L. E. Galejs and E. J. Kass, "Color Doppler Ultrasound Evaluation of the Acute Scrotum," Techniques in Urology, Vol. 4, No. 4, 1998, pp. 182-184.

[23] S. Strauss, R. Faingold and H. Manor, "Torsion of the Testicular Appendages: Sonographic Appearance," Journal of Ultrasound in Medicine, Vol. 16, No. 3, 1997, pp. 189-192.

[24] P. K. Hegarty, E. Walsh and M. O. Corcoran, "Exploration of the Acute Scrotum: A Retrospective Analysis of 100 Consecutive Cases," Irish Journal of Medical Sciences, Vol. 170, No. 3, 2001, pp. 181-182.

[25] M. Blaivas, P. Sierzenski and M. Lambert, "Emergency Evaluation of Patients Presenting With Acute Scrotum Using Bedside Ultrasonography," Academic Emergency Medicine, Vol. 8, No. 1, 2001, pp. 90-93.

[26] M. Blaivas and P. Sierzenski, "Emergency Ultrasonography in the Evaluation of the Acute Scrotum," Academic Emergency Medicine, Vol. 8, No. 1, 2001, pp. 85-89.

[27] M. Blaivas and L. Brannam, "Testicular Ultrasound," Emergency Medicine Clinics of North America, Vol. 22, No. 3, 2004, pp. 723-748.

[28] E. J. Kass, K. T. Stone, A. A. Cacciarelli and B. Mitchell, "Do All Children With an Acute Scrotum Require Exploration?" The Journal of Urology, Vol. 150, No. 2, 1993, pp. 667-669.

[29] G. Liguori, S. Bucci, A. Zordani, S. Benvenuto, G. O1landini, G. Mazzon, M. Bertolotto, F. Cacciato, S. Siracusano and C. Trombetta, "Role of US in Acute Scrotal Pain," World Journal of Urology, Vol. 29, No. 5, 2011, pp. 639-643.

[30] K. A. Johnson and K. C. Dewbury, "Ultrasound Imaging 
of the Appendix Testis and Appendix Epididymis," Clinical Radiology, Vol. 51, No. 5, 1996, pp. 335-337.

[31] M. Baldisserotto, J. C. de Souza, A. P. Pertence and M. D. Dora, "Color Doppler Sonography of Normal and Torsed Testicular Appendages in Children," American Journal of Roentgenology, Vol. 184, No. 4, 2005, pp. 1287-1292.

[32] S. J. Park, H. L. Kim and B. H. Yi, "Sonography of Intrascrotal Appendage Torsion: Varying Echogenicity of the Torsed Appendage according to the Time from On- set," Journal of Ultrasound in Medicine, Vol. 30, No. 10, 2011, pp. 1391-1396.

[33] O. Cappele, A. Liard, E. Barret, B. Bachy and P. Mitrofanoff, "Epididymitis in Children: Is Further Investigation Necessary after the First Episode?" European Urology, Vol. 38, No. 5, 2000, pp. 627-630.

[34] L. A. Graumann, H. G. Dietz and M. Stehr, "Urinalysis in Children with Epididymitis," European Journal of Pediatric Surgery, Vol. 20, No. 4, 2010, pp. 247-249.

\section{Abbreviations \\ EO-Epididymo-Orchitis \\ US-ultrasound}

